\title{
Study on Learning Process Evaluation
}

\author{
Yong Luo $^{\text {ab* }}$, Jianping $\mathrm{Li}^{\mathrm{a}}$, Zheng Xie ${ }^{\mathrm{a}}$, Guochang Zhou ${ }^{\mathrm{a}}$, Wei Zhao ${ }^{\mathrm{b}}$ and Xiao Xiao ${ }^{\mathrm{c}}$ \\ ${ }^{a}$ College of Science, National University of Defense Technology \\ Changsha, China; \\ ${ }^{b}$ Hunan Provincial Key Laboratory of Network Investigational Technology \\ Changsha China; \\ ${ }^{c}$ Higher Education Press, Beijing, China; \\ Email: yngluo@163.com*Yong Luo
}

\begin{abstract}
MOOC is currently facing the challenge of high dropout rates. The irrationality of course certification model is an important reason. This article analyzes the current major MOOC certification models and the various challenges. We divide the MOOC certification model into four categories: course certification, effective learning certification, credit certification and course group certification. This paper proposes a certification model based on learning achievement, which is an evaluation based on the learning process. Learners will gain a gaming experience during their learning process. This model improves their participation and motivation. Through designing learning rankings, learners can compare other people's learning achievements in real time and improve their own plans. Finally the goal of improving effect is improved.
\end{abstract}

Keywords-MOOC; Learning team; Group learning; Passing rate

\section{INTRODUCTION}

MOOC is the large open online courses. Courses are provided by internationally renowned university and shared through the network [1]. It enables global sharing of quality course. Coursera, Udacity, edX are currently the three largest providers in the world.

Its philosophy is to enable global learners to share quality resources through information technology and web technologies [2]. MOOC have a complete set of teaching modes. Including registration, watching video lectures, quizzes, assignments, discussions, exams, graduation, certificates and other processes. These teaching models to learners brought a new experience and give chance to get involved in high education. At the same time, through sharing the resources, the college courses can also be improved.

Although it has been rapid development and recognition, but there are still many controversies. From the history of online education, changes in learning resources promote the revolution in learning styles. How to use online course resources scientifically is a common concern. MOOC is currently facing such problems as high dropout rates, low resource utilization and lack of an effective profit model. MOOC courses often enroll tens of thousands of students, but often the last certificate students only $1 \%$.

At present, the MOOC certification model is simple, and

Supported by the Open Research Fund of Hunan Provincial Key

Laboratory of Network Investigational Technology, Grant NO.

2017WLZC003. the degree of recognition of the certificate needs to be improved. Therefore, it is necessary to explore and study the MOOC certification model so that it can truly reflect the learning effect. Only such a certificate can be recognized by the community. Therefore, the study of the MOOC certification model has a very positive effect on its development.

At present, there are few studies on the MOOC certification model. Some recent studies include the following. Formanek (2018) [1] analyzed and studied motivations of college students studying MOOC courses. Lloyd et al. (2017) [2] calculated and analysed MOOC course learning behaviours and learning performance data. Andrew (2017) [3] based on the characteristics of chemistry courses, studies how to enable more effective communication among learners and improve their learning in MOOC. Alario-Hoyos (2016) [4] analyzed MOOC learning behaviours and its effectiveness as a means of assessing MOOC. Hone et al. (2016) [5] analyzed the factors affecting the retention of MOOC learning through the questionnaire. Mackness et al. (2015) [6] analyzed the prospects and challenges of MOOC development. Margaryan et al. (2015) [7] analyzed MOOC teaching quality and its influencing factors. Phan (2016) [8] analyzed students' performance in participating in the MOOC course. And do a comparative study of classroom learning and online learning. Bart Pursel et al. (2016) [9] studied MOOC learners' demographic data, learning behaviours and course interaction data. Stich (2017) [10] analyzed the MOOC in the United States and found that the platform blindly pursued the number of courses but neglected the service to learners.

This article describes the existing MOOC certification model and analyzes the problems faced by certification. We propose a process evaluation program. And apply online learning theory to study the impact of certification model on the development of MOOC. 


\section{PROBLEMS OF COURSE CERTIFICATION}

Course assessment and certification is a necessary part of setting up a course. Online courses also have the need for scientific certification of learners. It is an affirmation and assessment of the learners' time and effort, as well as the knowledge level.

The certification method under the classroom teaching model basically adopts the assessment model. This model is designed for classroom learners and is formed through the long-term development of education and teaching. Although this model also has one or more defects, its status and role cannot be replaced. At present, the value of MOOC's course certificate and social awareness are not high. It is mainly honor certification and commemorative significance. The social recognition of certificates is not high. The main reasons are as follows:

\section{A. The difficulty of obtaining the MOOC course certificate}

To a large extent, the online learning model cannot be compared with classroom teaching. Direct interactions are difficult to achieve in MOOCs. Students' feedback on learning is difficult to get a teacher's quick response. Although there are course forums, it is still difficult to solve the needs of learners to answer questions in the curriculum. This leads to the depth of the course study is far less than the classroom teaching mode. It is not difficult to understand why MOOC course certificate is easy to obtain. On the other hand, the lack of supervision of the MOOC learning process makes it difficult for learners to insist. Now almost all MOOC platforms have a completion rate of less than $10 \%$. An important reason for keeping these learners out of the complete learning curriculum is the large number of lesson exercises. Therefore, in order to attract more learners, many course platforms and course developers artificially reduce the difficulty of course assessment and homework. Some MOOC platforms consider the economic benefits. In order to attract learners to pay for their studies, the requirements for the accuracy of after-school assignments will be reduced. Some courses require only $35 \%$ of the correct rate to apply for a certificate.

\section{B. The social recognition of MOOC's course certificate needs to be improved}

The development of MOOC has just started and its role has not yet been universally recognized by the society. Even the vast majority of employers do not know the existence and value of MOOCs. Without being understood, it will not be accepted. MOOCs also need long-term development to reflect their own value.

MOOC's learning model and its role in the development of society's human progress are not to be questioned. It is necessary to proceed from the country or the entire education system and give a reasonable evaluation of the MOOC certificate. Only in this way can we accelerate the development of MOOC and exert its maximum effectiveness. It can help improve the quality of the entire society and advance human civilization and development.

\section{MOOC lacks rigorous assessment mechanism and there is a possibility of easy cheating}

The MOOC platform lacks a real-name authentication mechanism and cannot technically confirm the authenticity of the exam. Learners can seek various illegal ways to pass the course assessment. It can be imagined that if the MOOC certification is approved, the learner can be provided with help in job search, promotion, etc., then the examination method that comes with integrity will be formed. It can even form a completed chain of illegal interests. This completely destroys the fairness or effectiveness of the MOOC certificate. Although this result is very cruel, it still has to be admitted that there is currently no technology that meets the MOOC certification requirements.

\section{According to the technology, assessment content is single and cannot fully reflect the student's level;}

The test questions of the MOOC platform are mainly based on objective questions, which are determined automatically by the machine. But for mathematics courses, reasoning and proof are needed. The subjective answers are currently used by students to evaluate each other. This way, it is difficult to ensure the consistency and accuracy of the score marks.

Only improving the accuracy of the automatic scoring system can improve the efficiency of scoring, and it can also fully assess the student's learning level.

Although there are many problems and deficiencies in the MOOC certificate, its role should not be ignored. A certificate of completion can inspire and sustain motivation and make learning more effective. To a certain extent, the learning results are more concrete and tangible. It can enhance the purpose of learning and attract learners to devote more energy and time to learning.

\section{COURSE CERTIFICATION MODELS}

At present, the MOOC certification model can be divided into course certification, effective learning certification, credit certification and course group certification.

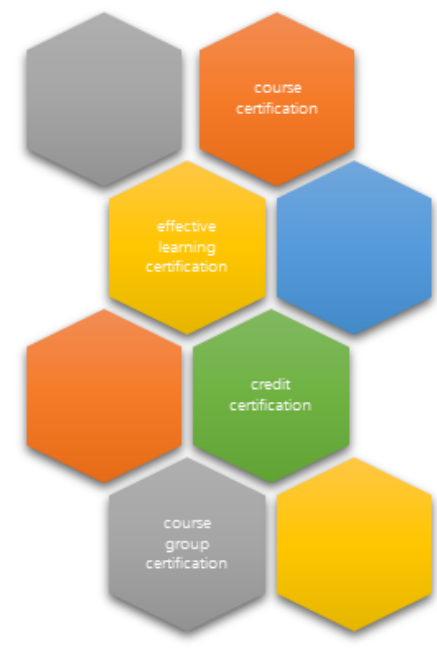

Fig. 1 The MOOC certification model 


\section{A. Course certification}

Most of the existing MOOC platforms are models of course certificates used. After the learner completes a course, the course platform will issue a digital certificate. This certificate can prove that the learner passed the MOOC course of study. Of course, the forms of certificates issued by various platforms are also different, but their essence is the same. Some course certificates include not only results but also detailed scores for each part. Even some of the certificates will outline the course content.

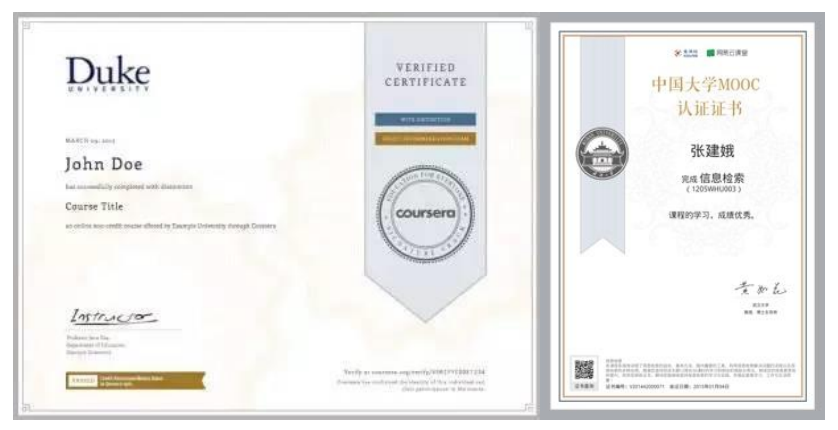

Fig. 2 Course Certificate

\section{B. Effective learning certification}

Effective learning refers to the act of acquiring knowledge. For effective learning certification, MOOC does not provide any form of proof of completion. MOOC evaluates the occurrence of its learning behavior and the resulting learning effects. Effective learning certification is also a self-directed learning goal advocated by MOOC. The learning content is selected according to the learner's interest in learning. Of course, the core of these learning behaviors is embodied in its effectiveness. Watching course videos, completing assignments, and participating in discussions during the learning process are all important reflections of learning outcomes. In fact, the high dropout rate and low completion rate of MOOC courses are objectively existing. The vast majority of MOOC learners $(99 \%)$ have failed to complete the course of study. Therefore, the evaluation and certification of effective learning is a very important task.

\section{Course group certification}

At present, the MOOC platform also begins to explore the course group that provides a series of courses. Such as edX's "XSeries" course group, Coursera's "special courses" course group, and Tsinghua University launched in the financial sector. The course group can be understood as a professional course system of the MOOC platform. This is also the inevitable development of MOOC. None of the research and application fields can be fully covered by a single course. It is necessary to establish a systematic course system so that a beginner can completely master the knowledge in the field. Employers also want employees to systematically study knowledge in a certain area. A series of courses can enhance learners' ability more than a course.

\section{Credit certification}

MOOC users are not limited to school students, but they are an important use group for MOOCs. How to improve students' use of MOOCs has attracted the attention of universities and researchers. Therefore, with the rapid development of MOOC, credit certification issues have been raised. How can students get college course credits by learning MOOC courses? Its credits can be equivalent to credits for the subject teaching course. Credit certification can undoubtedly inject new vitality into university training courses. Globally high-quality teaching resources can be applied most quickly to the student cultivation of our school.

\section{LEARNING PROCESS EVALUATION}

Due to MOOC technical reasons, many learning behaviors have cheating loopholes. Because of the lack of accuracy in assessment and course certification, the authority of the course certificate is affected. Currently edX and Udacity's solution is to use offline exam center assessment. It can partially solve the assessment of the requirements of authenticity, but it will also limit the development of MOOC. Therefore, we need to seek a scientific and reasonable online evaluation model to solve this problem.

This article will propose a learning process assessment system. It takes the learning process evaluation and effective learning as the basis for assessment and improves student enthusiasm through the establishment of a learning achievement system.

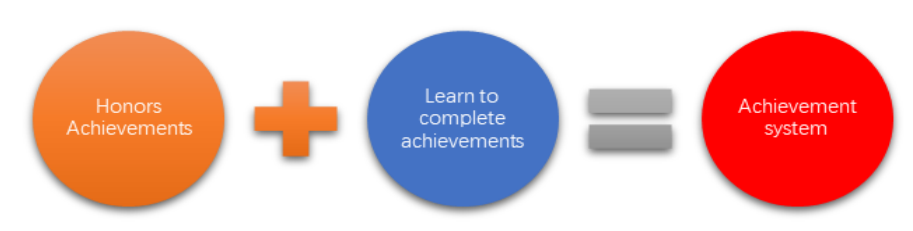

Fig. 3 Learning Achievement System 
The learning achievement system here includes learning achievement accomplishment and course honor achievement. Learning behavior achievements are targeted at behavior settings, including watching videos, completing quizzes, completing unit tests, and completing course assessments. Course honors achievement refers to the assessment of the quality of the accomplishment of the learning task.

Students can only obtain learning achievement accomplishment if they complete the study of related content. These achievements correspond to the learning of the content of the course. Obtaining these achievements is the basic condition for obtaining a certificate. Of course, these achievements are hierarchical and correspond to the hierarchical relationship of curriculum knowledge. The model of achievement was introduced to increase the sense of learning and the challenges of learning. For example, taking the completion time and accuracy as the rank of the performance can make students feel the joy of the challenge.

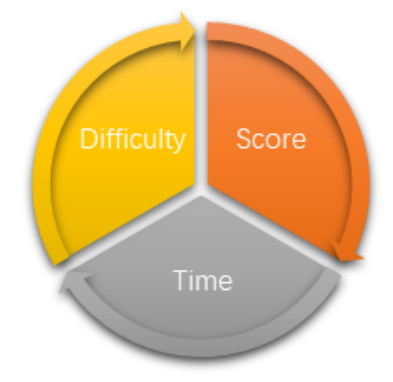

Fig. 4 Ranking parameters in challenge mode

In addition, in order to further improve the learning challenges and fun. We designed a student's online learning evaluation ladder ranking. The ranking includes the degree of difficulty, grades, and completion time. The system gives the ranking of learners based on these three indicators. All learners can understand the level of learning of other students. Learners adjust their study plan by comparing. Let learners feel the existence of competitive pressure and stimulate their enthusiasm for learning.

\section{CONCLUSION}

Although MOOC does not have a classroom learning mode, it has found that the course certificate has a great influence on the learning effect. The conditions for obtaining the course certificate led them to not have enough motivation to persist in learning. Another reason is the technical defects and personal integrity, making the course cheating loopholes. The social recognition of certificates needs to be further improved. The process evaluation method can improve the reliability of the certification, and it is more scientific and effective.

In addition, through the learning achievement ranking mechanism, it can further enhance the motivation for learning. Let more outstanding students show their learning results to others. In summary, process assessment certification is very meaningful for the development of MOOCs.

\section{REFERENCES}

[1] Formanek, M., Wenger, M., Buxner, S., Impey, C.D. (2018). Motivational Differences between MOOC and Undergraduate Astronomy Students. American Astronomical Society, 231.

[2] Lloyd, P. R. (2017). Participation patterns in a massive open online course (MOOC) about statistics. British Journal of Educational Technology, 48(6), 1295-1304.

[3] Andrew, A. (2017). The nature and level of learner-learner interaction in a chemistry massive open online course (MOOC). Journal of Computing in Higher Education, 29(3), 411-431.

[4] Alario-Hoyos, C., Muñoz-Merino, P. J., Pérez-Sanagustín, M., et al. (2016). Who are the top contributors in a MOOC? Relating participants' performance and contributions. Journal of Computer Assisted learning, 32(3), 232-243.

[5] Hone, K. S., \& El Said, G. R. (2016). Exploring the factors affecting MOOC retention: A survey study. Computers \& Education, 98, 157-168.

[6] Mackness, J., \& Bell, F. (2015). Rhizo14: A rhizomatic learning cMOOC in sunlight and in shade. Open Praxis, 7(1), 25-38.

[7] Margaryan, A., Bianco, M., \& Littlejohn, A. (2015). Instructional quality of massive open online courses (MOOCs). Computers \& Education, 80, 77-83.

[8] Phan, T., McNeil, S. G., \& Robin, B. R. (2016). Students' patterns of engagement and course performance in a massive open online course. Computers \& Education, 95, 36-44.

[9] Pursel, B. K., Zhang, L., Jablokow, K. W., Choi, G. W., \& Velegol, D. (2016). Understanding MOOC students: motivations and behaviours indicative of MOOC completion. Journal of Computer Assisted learning, 32(3), 202-217.

[10] Stich, A. E., \& Reeves, T. D. (2017). Massive open online courses and underserved students in the United States. The Internet and Higher Education, 32, 58-71. 